\title{
THE ETHOS OF THE AUTEUR AS FATHER OF THE FILM CRAFT - ON MASCULINITY, CREATIVITY AND THE ART OF FILMMAKING
}

\author{
Shlomit AHARONI LIR $\mathbb{1}^{*}$, Liat AYALON \\ The Louis and Gabi Weisfeld School of Social Work, Bar-Ilan University, \\ Max ve-Anna Webb str., 5290002 Ramat Gan, Israel \\ Received 20 January 2021; accepted 24 May 2021
}

\begin{abstract}
Research of the world of cinema often deals with the manner in which movies replicate the social balance of power, creating a symbolic order based on an essentially masculine world-view that puts the man at its center. The price women pay for this phallocentric approach - their persistent objectification in cinema, and the very small number of female screenwriters and directors - has become a much-discussed topic in contemporary research. However, the question of the price paid in the male artistic creation process has yet to receive the attention it deserves.

This qualitative study addresses the lacuna in contemporary research, with reference to three metafictional films that focus on male directors, as an auteur for whom cinema is the pivotal center of their being: the Israeli film Peaches and Cream (2019, directed by Gur Bentwich), the Spanish film Pain and Glory (in Spanish: Dolor y gloria, 2019, directed by Pedro Almodóvar), and American film All That Jazz (1979, directed by Bob Fosse). They all are viewed as having an affinity with the ancient Greek comparison of male creativity with female procreativity, which is still reflected in contemporary studies.

The films paint a picture of the male creative process shadowed by a sense of danger and loss of self. All three expose the feelings of anxiety inherent in film directors' work, and the possible resultant breakdown, not only in an emotional sense but in a real, potentially fatal physical or medical sense as well. In all three movies, the director conceives of his ability to restore his sense of inner wholeness and male identity in a manner that contradicts the conventional balance of power, while customary power-relations are revealed as another road to loss of identity and sense of self. Each of the films ties the director's ability to renew his sense of personal wholeness to developing a relationship with his surroundings, facilitated by audience appreciation, critical praise, or empathy from those close to him - all of which reinforce his feeling of belonging and significance. Without these aspects, the "absolute artist", whose life revolves around his art, is shown to be at death's door, whether symbolically or in reality.
\end{abstract}

Keywords: absolute director, cinema and gender, directing and gender, masculinity and directing, metacinema, metafiction, price of glory.

${ }^{\star}$ Corresponding author. E-mail: lirshlomit@gmail.com

Copyright @ 2022 The Author(s). Published by Vilnius Gediminas Technical University

This is an Open Access article distributed under the terms of the Creative Commons Attribution License (http://creativecommons. $\mathrm{org} / \mathrm{licenses} / \mathrm{by} / 4.0 /$ ), which permits unrestricted use, distribution, and reproduction in any medium, provided the original author and source are credited. 


\title{
Introduction
}

The ethos of creativity as a male attribute was already popular in ancient Greece. In his Symposium, Plato (2003) writes of Socrates introducing a female figure by the name of Diotima of Mantinea, who compares the act of having a child, in which man and woman are equal partners, to the essentially masculine process of fathering an artistic creation as his endowment to future generations. This concept of the paternity of the artistic creation for the sake of legacy has persisted in different historical periods, and, in the view of Gilbert and Gubar, is still relevant today:

\begin{abstract}
"Finally, that such a notion of 'ownership' or possession is embedded in the metaphor of paternity leads to yet another implication of this complex metaphor. For if the author is owner of his text and of his reader's attention, he is also, of course, possessor of the subjects of his text, that is to say of those figures, scenes, and events - those brain children - he has both incarnated in black and white and 'bound' in cloth or leather. Thus, because he is an author, a 'man of letters' is simultaneously, like his divine counterpart, a father, a master or ruler, and an owner: the spiritual type of a patriarch, as we understand that term in Western society" (2020, p. 7).
\end{abstract}

With respect to gender, much has been written about the way the dominant patriarchal order operates in cinema, identifying the viewers as males, for whom women are an object of interest (Mulvey, 1989, pp. 14-26). The ethos of the creative man, producing a legacy for future generations, is evident inter alia by the small minority of women directors and film-makers, even today (Statista, 2021). Nevertheless, the price exacted from male directors in the course of their work has yet to receive fair examination. This perception of the male director as a "founding father" raises questions about the connection between gender and film direction, and the way male directors regard their craft from their particular perspective. What does their cinematographic work mean to them? How does their role play out when they make movies of an autobiographical or metafictional nature? And particularly, what is the emotional and physical price that comes with the concept of the man as artistic creator?

This qualitative study addresses those questions by examining three metafictional films that hold up a mirror to the way men view the world of their creations and themselves as creators. The first film, Peaches and Cream, directed by Bentwich, takes place in the course of one night, ending the next day. A director, distraught by the impending failure of his new movie, tries everything possible to salvage it, but ends up in hospital with a heart attack, fighting for his life. The second, Pain and Glory, by directed by Almodóvar, describes an ageing director whose multiple painful ailments have kept him from film-making for many years, up to the time when the screening of a restored version of his old movie motivates him to come back and deal with his past. In the third film, All That Jazz, directed by Fosse, the director-choreographer is simultaneously and intensely directing a movie and a stage production, but his heart gives in and he is confined to a hospital bed until his death.

We selected these three films because they exhibit similarities, grappling with the act of directing and the meaning of cinema in a manner that allows examination of the questions that engage this study. Each of the films is fundamentally autobiographical; at the heart of each stands the character of a well-known middle-aged director, who suffers from anxiety 
and illness. He reflects the actual film-maker, an auteur, ${ }^{1}$ for whom directing and cinema play a crucial part in his life.

The plot in all three films is metafictional and deals with the meaning of the creative process for each director; this, with a recurring motif of film-within-film and an inner world that finds expression in the outer world. In parallel, each of the films examines the meaning of directing in relation to aspects of masculinity, fame, and the price exacted by the creative process.

Another important aspect the three films have in common is their echo of Federico Fellini's film, 81/2 (1963). This classic cinematic masterpiece caught the attentions of film historians and critics and is regarded as one of the greatest films of all times (Conti \& McCormack, 1984; Bondanella, 2002). The film showcases a successful, famous film director struggling with the chaos of film-direction and his own lack of clear direction for the film he wants to make. The metafictional aspect of Fellini's film, and its status as a cinematographic milestone - transforms it into an inspiration for various subsequent metafictional films (Conti \& McCormack, 1984), including those discussed in this study. The relevance of this film to the three films discussed in this study is not only due to autobiographical aspects depicted in all movies, but also more importantly, because of the fact that it concentrates on the nature of cinematic artistic creation from an auteur's point of view - a theme shared by the three movies we inspect.

The fact that our three selected films come from three different locales, Israel, Spain and the United States (US), allowed us to examine common aspects that rise above differences of geographical location. The two different eras in which the films were released - Fosse's All That Jazz preceded the other two films in our study by forty years - added an important dimension of decoding the gender connections over time, thus aiding us in exploring the norms of portrayed masculinity of the "absolute director", past and present. Similarly, the differences between Bentwich's and Fosse's films, with their heterosexual heroes, and Almodóvar's, whose main character is homosexual, enabled us to explore the gendered aspects of the creative self in the three films.

\section{The ethos of the male creator}

Throughout history, the fundamental perception of the artist has been in its essence that of a male image (Gilbert \& Gubar, 2020; Woolf, 2015). The character of the artist has been based on three main principles: totality, an unconscious preference for male creativity, and masculine modes of behaviour for advancement and achievement of status. The image or expectation of the ideal worker reflects male models of behaviour, and this is applied to the ideal artist as well. The work of the artist demands absolute dedication; that, and the pressure of unconventional timetables, for example, is a situation that better suits a man. The fact is there are more men than women in almost every field of art (Miller, 2016). There is an expectation of only medium intensity from female artists, so as not to "interfere" with their domestic role; the male artist, on the other hand, is free to dedicate himself entirely to his work. Although artworks are supposedly gender-neutral, there is a clear male bias in art, as in

\footnotetext{
${ }^{1}$ The term refers to a film director, who applies a highly centralized and subjective control to many aspects of his creative work (see Caughie, 2001).
} 
other fields. Genius and eccentricity, which are highly valued in the art world, are regarded as male characteristics. There is in general a possibly unconscious tendency to prefer the works of a male artist to those of a female, regardless of their quality. The fact that art appreciation is subjective makes gender preference more easily influenced (Miller, 2016).

In the cinematic world, male dominance has been historically maintained and directing, among other professions in the film industry, has been perceived as being inherently masculine (Ward Mahar, 2001). The synonymity of film directing with masculinity has been strengthened by the rise of the auteur theory in 1954. This concept emphasizes the authoritative place of the director as the father of the filmcraft. This perception of the director as an auteur, rather than as a craftsman, strengthens his place as an artist who dominates the work, is responsible for the film's scenarios and dialogues, habitually writing and inventing the storyline (Staples, 1966-1967). Whereas the masculine aspect of the auteur was not openly part of the characterization of film directors, it was insinuated in the lists of male directors who were conceived as auteurs as well as in the writing of André Bazin, who wrote the first book on this subject in 1957, affiliating the auteur with masculine heritage of prominent authors and artists, stating the desire to find the "Shakespeares and the Rembrandts of film" (Staples, 1966-1967, p. 4).

Feminist studies over the years have tackled the problematic perception of the artist as a male or father-figure, and the price women pay because of it (Miller, 2016; Gilbert \& Gubar, 2020; Irigaray, 1993). The ethos of the male artist carries its own price, however. The Western perspective glorifies the image of the tormented artist who creates despite his emotional issues, but also perhaps because of them (Borowsky Junge, 2016). Studies have found a tendency among artists to decide things in haste, and less of an ability to solve problems (Papworth et al., 2008). The correlation between art and emotional or psychotic disorders is so strong in the public perception that artists have sometimes felt moved to feign madness in order to preserve the image of an authentic artist (Borowsky Junge, 2016). As the aphorism attributed to Aristotle puts it: "No great mind has ever existed without a touch of madness". The idea is not divorced from reality, given the high incidence of psychopathy among artists (Ramasubba Reddy et al., 2018). But conventional treatment, especially with medication, is perceived as harmful to an artist's originality and ability, and there is fear that it could destroy the artist's creativity altogether (Sussman, 2007). In contrast, art connects to empowerment, self-knowledge and even self-healing (Kost, 2019), can create a connection between the self and the world, and, using the connection as a conduit, heal emotional wounds (Borowsky Junge, 2016).

This point of view sharpens the question of the study regarding the meaning of creating art for its creator. Does it have the power to heal, or is there danger lurking alongside that power as well? This paper explores these questions from a gender perspective, and examines the image of the absolute artist and his position in the life cycle by referencing three metafictional films made at different times and in different geographical locations.

\section{Findings}

Films: 1. Peaches and Cream, 2019, directed by Bentwich, Israel; 2. Pain and Glory, 2019, directed by Almodóvar, Spain; 3. All That Jazz, 1979, directed by Fosse, US. 
An analysis of the three films produced three primary interwoven themes common to all three works.

Film direction as life, and life as film direction: Each of the films interweaves aspects of imagination, past memories and dream in the reality of the movie. The character of the director is described as moving between fiction and reality, blurring the boundary between the actual and the imagined.

The internal externalized: In each of the films, the ethos of the director as the father of the artistic creation finds expression in the way the filmmaker signs the work as his own intellectual creation, as if he had fathered it.

Saving the film-maker: Investing himself in the work while blurring boundaries, and the director's absolute involvement in the world he himself has created, are presented in all three films as a threat of loss of self - and possibly his physical self as well. All three films focus on the director's struggle to regain his sense of wholeness.

\subsection{Film direction as life, and life as film direction}

Each of the three films is metafictional, in a manner that positions the director as a masculine auteur, who designs his work in his own personal image. This is evident not only in the sense of their being movies about movies, but also by the fact that the films-within-the-films are directed by the director-character in them, and sheds light on how he relates to his world of art, from a personal perspective. None of the films make hermetic differentiation between the professional director and his private persona, between film direction and real life. Instead, the two realms are shown intermixed, each intruding into the other, sometimes leaving the boundaries between what is real and what is staged unclear. This is seen in the metafictional elements in each film, the blurring of boundaries between reality and illusion and the price of the blurring between the worlds. We thereby examine how this blurring is expressed in each of the films.

The opening scene of the movie Peaches and Cream is set during a cinema screening, making the metafictional aspect of the work clear from the start. The font and design of the subtitles in the film-within-a-film are identical to those used in the poster of the real movie, creating a sense of a redoubled world of fiction. This sense, which bundles together the real world and a fictional one, is intensified when silhouettes of two whispering characters on the screen-within-a-screen, weaving their way through the seated audience, simulate the real situation of movie late-comers. The name of the film-within-a-film is exactly that of the reallife movie. The silhouettes not only sharpen the immediate reflexive response that creates the cinematographic work, but adds another, deeper layer, by turning attention to questions that touch on the meaning of truth, and the relation between fictional and real worlds. Is cinema a world of fantasy and illusion - silhouettes that are far from reflecting reality - or does the image have the power to represent the actual world? ${ }^{2}$

\footnotetext{
${ }^{2}$ In Plato's allegory of the cave, shadows of figures are used to demonstrate the difference between illusion and reality, between perceived reality that is conceived as truth and the reality outside the dark cave which indeed represents truth (1968, pp. 193-220).
} 
Peaches and Cream poses this epistemic dilemma of integrating the actual, living, bustling aspect of life with the world of filmcraft. The two figures the audience meets in the opening scene of the movie do not remain shadowy. From black silhouettes on a white background, images whose whispers are heard in the dark cinematic space, they are picked out by a spotlight that illuminates their features and their bodies, imbuing them with dimension and color. While still moving to a seat on the steps, and then to the projection booth, they move around the cinema hall, and finally take their leave. This symbolic cinematographic leap, from two-dimensional figures to fully rounded ones, from reflections in a movie theater to the bustle of life outside it, deepens our insight that, for the film director, on-screen and off it, pre-production and post-production, cinema and life are inseparably intertwined. The insight becomes more acute when we realize that the director of the film-within-the-film, Zuri Shostak, and the film editor of the film-within-a-film, Inbal Kaplan, are played by the director and film editor of the real film, Gur Bentwich and Maya Kenig.

In the movie Pain and Glory, Salvador Mallo, the director of the film-within-the-film lives isolated in his home in a manner that creates an unmistakable boundary between interior and exterior, supposedly protecting him from blurring boundaries. But even in his ostensibly protected home, reality and fiction become entangled, as he sinks into childhood reveries, and flashbacks to past events, in a manner that blurs the boundaries between real memory and fictitious reconstruction. This aspect tremendously enhances the reflexive process created by the film, bringing forth the question as to whether the hero's wallowing in reminiscences of the past is authentic, or whether the memory has been scripted and staged by him as director. Thus, once again, Plato's cave allegory, which discusses shadow and substance, and questions the nature of knowledge (1968, pp. 193-220), is called into play. The question is not merely hypothetical, however. It has real meaning for understanding reality, and walking the world with an identity and an ability to discriminate clearly the actual from the illusory.

The process of regression into the world of creative arts is actualized in Pain and Glory by the inability to overcome the residues of the past. Salvador Mallo's act of venturing out of the house is only in order to revisit the past. He pulls himself together and leaves the house and the city to meet Alberto Crespo, an old acquaintance who played the leading role in Salvador Mallo's first movie, "Sabor" (in English: "Flavor"), over thirty years earlier. The two meet just before a festive retrospective in Madrid of films from the 1980s, to which Salvador Mallo asks Alberto Crespo to accompany him. In the encounter it transpires that the decades have not soured the "flavor", as the original poster of the movie still graces the wall of Alberto Crespo's apartment; and Salvador Mallo comments that it took 32 years to come to terms with Alberto Crespo. The reunion, however, at least at first, leads to doing heroin together, which intensifies Salvador Mallo's sense of floundering in an imaginary world, and his inability to deal with reality. Following that, he meets his new "Sabor" audience from afar, by phone, and past bitterness and grievances surface, as Salvador Mallo, once again, criticizes Albert Crespo's role in that first film. The danger that Arendt (1998) points to, regarding the unexpected consequences that actions can produce and the price they can exact, ${ }^{3}$ is portrayed in the

\footnotetext{
${ }^{3}$ Arendt talks about the way an action in the world can produce unexpected consequences and block a further action, if there is no releasing act of forgiveness.
} 
film in the way the past imprisons the director in the present. The film was completed thirty years earlier, but the vulnerability that accompanies the process is carried on to the present.

In the film All That Jazz, the integration of the real world and the world of the stage is present from the opening of the film, whereas voices in rehearsal for a show, tuning of instruments, and the hubbub of people are heard, while the movie's subtitles appear on a black screen. Cutting through the sounds, a choreographer's voice is heard - "OK, one more time. From the top. Six beats, all right? One, two, three, four. One, two [...]". These stage instructions are the cue for the big-band music that is the prelude to the lighting-up of the movie title - simulating a flashy theater-entrance show sign.

These aspects of show and rehearsal are staged throughout the film, with scenes that repeat themselves, in a manner that emulate rehearsals for a live performance. The showbiz effect at the beginning of the movie takes on another dimension as the first scene describes the morning ritual of Joseph "Joe" Gideon, the director of both the film-within-the-film and the stage show within it. The repetitive scene - playing Antonio Vivaldi, popping pills, taking a shower - ends with a look in the mirror, the declaration "It's showtime, folks!" and a movement of spread hands, in a basic gesture of an actor on stage, all complete the notion of a performance before an imaginary audience. William Shakespeare's famous words - "All the world's a stage, and all the men and women merely players" - defines Joseph "Joe" Gideon's life, not as metaphor but in real terms. The opening scene, with Vivaldi's music, reappears time and again throughout the film, creating a dramatic, intense statement that grounds the understanding that for Joseph "Joe" Gideon, from the time he rises, life is part of a performance, with him as director, participant and primary audience.

This repetitiveness reflects Joseph "Joe" Gideon's sense of being stuck in a recurring timeloop that his artistry does not break through. Instead, the cycle exhausts Joseph "Joe" Gideon, who seems increasingly worn out each time the scene recurs, inviting the realization that he is imprisoned within the creative world. The narrative of the plot reinforces the impression that he lives and functions as a player who directs himself in various encounters in his life, while losing the connection with reality and the ability to sustain real, reciprocal relationships.

The interweaving of the worlds of fiction and reality - the movie and the show with the life that goes on beyond them - continues throughout the film, finding expression as well in the characters that inhabit Joseph "Joe" Gideon's world. Apart from the hospital scenes, none of the figures in his life exist outside the entertainment business. Those who are close to him, including his girlfriend, daughter and ex-wife, are intrinsic to the production that completely controls his life: they are the producers, the investors, they compose part of the audience, and are those who dance and act under his guidance. In fact, even the characters he encounters in hospital are swept into the world of the stage as he starts to direct them. This stands out in one scene with a male nurse in which they rehearse an imaginary number. And while Joseph "Joe" Gideon is fighting for his life, he cannot cut himself off from the world of the stage that so dominates his being, and relate to the physicians' diagnoses and advice with the seriousness they deserve. He wants to stop the madness but does not know how, and death thus becomes more and more appealing. 


\subsection{The internal externalized}

Fellini's metafictional movie $81 / 2$, which is a milestone in cinematic stream of consciousness emphasizes his position as an auteur, and opens an aperture into the director's mind, inter alia through the interplay of surrealistic dreams and fantasies, immediately evident from the opening scene. Guido Anselmi, the director of the film-within-a-film, is stuck in a traffic jam when smoke starts spewing out of his car. He manages to extricate himself and soar into the clouds, when a rope, held at one end by a member of the film production team, draws him back to earth, until he falls and almost drowns in the sea. Entering the director's world does not just occur in the stream of consciousness, in which his dream actualizes the real-world feeling of suffocation on the one hand, and of being lost in the world of the imagination on the other. Right after the dream scene, Guido Anselmi wakes up to a physical examination in a doctor's office, with a nurse in attendance. In all three films under discussion, the aspects of fantasy, dream and memory highlight the artistic creator as one who lives in a world of symbols, nourished by images whose appearance on screen opens a keyhole view into his soul and inner world. When entry into the auteur's inner world becomes a physical production, it reinforces the analogy of his giving birth to his creation, and for that he is likely to pay a physical price.

In Peaches and Cream, the inner world of Zuri Shostak emerges in recurring illusionary scenes of being the sole passenger on a flight to Iceland. Dressed in a tuxedo, he is en route to an event that he describes as the one he had dreamed of all his life: a gala showing of his film at a festival in Island. The repeated reference to the imaginary flight, while in reality his recent film has flopped and he has been told that he faces a possibly life-threatening heart attack, provides the entry-point into the director's consciousness. In his mind, the creative process continues, as he edits scenes on his imaginary flight, but the festive event to which he is supposedly flying reflects his craving for visibility, recognition and public acclaim.

The director's inner world is staged as an actual location in which significant, living, bustling creativity takes place - in parallel to his real life. This imaginary world is based on images and symbols that exist in the director's consciousness, reflecting his thoughts and feelings, while his illusory dream destination provides a substitute for his lack of love and recognition in real life. Thus the flight destination delights in the way it compensates for the failure in the present, but it also holds an inherent danger, since its meaning is a temporary refuge and a sense of control, side by side with the possibility of complete submission to this fictional world, and denial of reality and the concrete challenges it presents.

The entry to Zuri Shostak's inner world is not restricted to the realm of the imagination, but is staged by the medical scan of the body itself, with the image of his heart on the hospital monitor, in preparation for a catheterization procedure. This exposure of the interior of the body marks the "absolute creator" as the focus of the work. This entrance into the internal space emphasizes the body as part of the creative work, and the place of the creator as the one for whom the movie was made, literally within him. Following Ne'eman's (2008) analysis of how cinema reflects male envy of the female body as the source of childbirth, the cinematic focus on the interior body can be taken as a symbol of childbirth, viewing the interior world as holding potential for something new, but at the same time signifying a potentially 
life-threatening situation. The choice of life is acknowledged moments before the operation, at two separate levels that return to the analogy of creativity and childbirth. In the hospital elevator, Zuri Shostak proposes to Inbal Kaplan that they should have a child together, and on the way to the operating room, Mushon, the producer of the present film, has a suggestion for Zuri Shostak: "Write down everything that happened to you tonight. That will be your next movie [...] a movie about life, death and the cinema!".

In Pain and Glory, the allegory of a mesmerizing fictional world is made clear from the opening segment, which displays the credits in geometrical shapes on what seems to be an oil-paint background, stretching and forming waves, combining image and movement on the screen. The meaning of these pictures becomes clear later on, as the structure of the whole film is based on images and scenes that are decoded as the events unfolds. In the first scene of the movie, the opening images are transformed into a picture of a filled swimming pool, a motif that is continually interpreted throughout the movie as a symbol of cinema, childbirth and desire. In this opening scene, Salvador Mallo, the director in the leading role, is shown, eyes closed, sitting on a chair on the floor of the pool, completely submerged; there is no one else around. The line between imagination and reality is unclear. The film does not resolve the dilemma of the scene: is it a dream, a fantasy, or some kind of unconventional visit to the pool that actually took place in the film's real world? Instead, the scene plays out in a symbolic dimension at several levels. It earmarks the interior of Salvador Mallo as the focus of the plot, in a way that merges the unseen with the seen, the hidden with the overt, whereas a close-up of stitches along the length of his belly creates an analogy with the world of cinema. Relating to this motif, Ne'eman (2008) notes that the Latin term for surgical stitching (suture) is used in cinema for techniques that conceal the fact that the realism of a movie is actually achieved through a camera lens.

As Ne'eman (2008) mentions, while the cinematic suture is designed to hide the stich between the filmed scene and the manner in which it was produced, the real wound and scar remain in the body, preserving the memory of the injury. Almodóvar's choice of emphasizing the wound in the slow movement of the camera along the stomach was from the start a reference to the metafictional aspect of the film, and to its engagement in the director's inner world. Thus, establishing his place as an auteur, for whom his own body and soul consist of the staff that films are made of. The dissolve from this scene to childhood memories with his mother, near a natural source of water, reinforces the question on the connection between the authentic and the produced, the inner world of the mind and outside reality. However, as the movie unfolds, it becomes clear that Salvador Mallo is in great danger of losing his sense of self and retreating into a world of pain and a quagmire of memories.

In All That Jazz, Joseph "Joe" Gideon's inner world is manifested in frequent conversations that interrupt the linear narrative of the plot. His interlocutor is the beautiful young "Angelique", dressed in white, who appears on the stage of a rundown nightclub, surrounded by piles of discarded show accessories. As in the two other films, Plato's cave allegory (1968, pp. 193-220) is present here too, as the relationship between the imaginary world and reality is clarified. The white-clad theatrical character plays the angel of death, embodying Joseph "Joe" Gideon's desire to flee a reality that has become an endless, exhausting show. 
Apart from the world of the imagination, the inner Joseph "Joe" Gideon as the markedout location for the work, dramatized by a series of images in his morning-ritual scene: inserting a tape-cassette into the machine, Alka-Seltzer fizzing in a glass of water, a bottle of prescription pills, zoom-ins as he puts drops in each of his eyes, and a shot of the director in the shower, a wet cigarette stub dangling from his mouth. Further into the movie, the reference to the auteur as a body becomes more palpable as Joseph "Joe" Gideon undergoes an operation in which his stomach is opened and then stitched close again. A huge pad over the incision is the first hint of its existence. Later it is acknowledged by the two metal bars of the hospital bed, the line of blood on the pad as it is removed, and the way the doctors stand around smiling proudly as they look at the scar ("It came out nice"), their "triumph" approved by Audrey Paris, Joseph "Joe” Gideon's ex-wife ("That is beautiful. That is absolutely a beautiful scar, Dr. Gary!").

The scene recalls the view of director and cinema researcher Neeman (2008), with respect to "male envy" of the process of female childbirth. He maintains that the massive wounds and torn bodies in war movies are a simulation of the "wound" of childbirth in the woman's body. It can be said that the scenes in all three films which include exposure of the opened male body, symbolically correspond to the female process of childbirth; thus, insinuation the suggestion of the director as creator, a body that gives birth to the work. At the same time, all three movies suggest that the readiness of the filmmaker to open up completely, to experience fully the world of the imagination, and to try to produce an artwork from it, involves constant danger of loss and disintegration of the self, to the point of the loss of life itself.

\subsection{Saving the artistic creator}

In all three movies under discussion, film direction is presented as a vocation that demands complete devotion and dedication, which influence all parts of life. On the one hand, for the absolute director, as the auteur reflected in each of the films, filmcraft is presented as a means to gain control of reality and find expression for his inner world through the use of imagination, memory and dreams. On the other hand, film direction is represented as a dangerous occupation that can bring the filmmaker to the edge of the abyss. As the comprehension of artistic filmcraft in each of the films is parallel to the ability to open up to the world in a way comparable to childbirth - it carries somewhat similar risks of illness, withdrawal, and even death.

One of the characteristics common to all three films is the extremism of the character of the absolute director, for whom cinema is his only language, thus negating the possibility of functioning in a world other than filmmaking. The heroes of the films, who are in their 50s or 60s, experience illness and pain, depicted as a feature of uncompromising masculinity, which expresses itself in complete dedication to their work, to the point of being devoured by it. This in a manner that enhances the perception of masculinity related to genius and eccentricity in a self-endangering manner (Miller, 2016). What can rescue each director in that trajectory is the notion that he is seen and his work is recognized. When that notion is absent, the sense of being devoured by the fictional world can become real, like the possibilities of death in Peaches and Cream and All That Jazz, or the complete withdrawal from the world in Pain and Glory. 
The "totality" of Zuri Shostak, the hero of Peaches and Cream, establishes the character as a somewhat boyish man, in the lack of anchors in his life and his reaction to the failure of his film. The childish characteristics are apparent from the first scene, in which Zuri Shostak's character is revealed to the camera as a contradictory figure. On the one hand he has a thick beard, a social symbol of male authority and expertise (Reed \& Blunk, 1990; van der Land \& Muntinga, 2014). On the other hand, he is sloppily dressed in a childish yellow hood he borrowed from his girlfriend's son, three-quarter-length pants, and All Star sneakers. The dissonance continues throughout the film, in small nuances such as getting into pointless arguments and altercations with people around him, or going around with no money on him at all. But in fact, those contradictions connect to the total character he plays, as one who takes his truth all the way.

Being an absolute artist is also displayed in the absence of alternative anchors in Zuri Shostak's life. He is not married, has no children, or an alternative occupation. The process of making a film is described as creating an internal rupture, which could be healed by positive audience response, an encouraging review, or some other kind of empathy. But, the depth of this need is not seen by Inbal Kaplan, his girlfriend. In the taxi ride, Zuri Shostak and Inbal Kaplan analyze the audience reaction. In an attempt to console Zuri Shostak, she says that people thought the movie was nice. Zuri Shostak shoots back:

"Nice?! Is that what we made the movie for, so they'd say it was nice? We made it so it would blow their minds [...] What this means is unless there is some amazing miracle, the movie will dive into the graveyard of films that no one has heard or seen. That's what it means!".

Inbal Kaplan responds: "Even if a million people don't come, so what? Is that why you made the movie? So that the whole world would swoon before you?". She has touched on an important point, one that highlights the synonymity between the film and its director. "But how come you don't?", he asks rhetorically.

Inbal Kaplan's answer reveals the widening gulf between them, and her difficulty in understanding him and responding wholeheartedly. For Zuri Shostak, the film's burial is as if it were his own, suggested by his rejoinder, "I want to die". Despite the fact that his wish was nearly realized in the course of the movie, Inbal Kaplan perceives it as a call for attention, without understanding that Zuri Shostak has a real medical condition, and has a heart attack overnight. Zuri Shostak's totality is well known to his acquaintances, and when he announces that he is considering retirement, one says: "I'm sure you prefer to commit suicide first". But the price of directing and the need for visibility is not clear until the last moment, when the characters surrounding the director unite around him in his illness, in a way that tells him that he is visible and important in their lives.

In Almodóvar's movie, the hero withdraws from the world in his apartment, afflicted by a range of medical conditions, which he describes at length, illustrated by slides. Among them are insomnia, chronic throat infections, ear infections, acid reflux, a stomach ulcer, asthma, nerve pain, muscular pain in the hips, back pain, pain in the knees and shoulders, tinnitus, heavy breathing, migraines, and tension-induced headaches. In addition, the director describes a string of emotional issues: anxiety and panic attacks that add a dimension of fear to his life, and a long-running struggle with depression. In his words, the paintings on his wall are his main companions, but without filming, his life has no purpose. 
In this manner, Salvador Mallo is among the living, but he lives the life of a recluse at home, reads books in bed, and smokes heroin. His past as a director dedicated to his art is reclaimed through a rerun of his movie, "Sabor", and a solo performance by Alberto Crespo based on a story Salvador Mallo wrote. These presentations reveal his ardor, since childhood, to write and create, and his powerful desire to realize his passion, which, unlike the present, was supplemented by his many trips abroad. During a visit to his doctor, Salvador Mallo confesses that not a day goes by without his thinking about directing. The doctor says that people in worse condition than his continue to direct films. At that point another major reason for giving up directing surfaces: his mother's death. The reply reinforces the insight into the important role his mother played as a source of inspiration, and as someone who with one look could restore his sense of self.

The veneration that Salvador Mallo had for his mother is clear from the many references to her, in various scenes, as a source of inspiration. In this film, the ethos of the artistic creator as a father is not based on womb-envy; instead the allusion to his mother was as his personal source of creative inspiration. The mother's creative energy is sensed throughout the movie, among other things in her ability as a young woman without means to give their cave-abode the feeling of a warm home, and in the manner in which in her old age, she gives her son precise "directing instructions", including very detailed costume information in preparation for her death. This is true too of the symbolic aspect conferred on the craft of sewing, to which the film devotes two scenes: her darning a sock in the railway station, and giving Salvador Mallo her wooden darning egg as a farewell gift.

As previously mentioned, apart from mending clothes, a stitch or suture is the medical term for closing an incision after an operation, and, in the world of cinema, "stitching" a scene so that the camera remains outside the frame (Ne'eman, 2008). When Almodóvar unwraps the railway-station darning scene that was previously referred to as a memory, and presents it as a staged scene, he not only exposes the stitching that usually remains hidden, but also the parallel between his mother's stitching and his own as part of the director's craft. The opening scene, as noted before, shows stitches the length of Salvador Mallo's belly. These are not only evidence of an operation he has undergone, but they reveal the director as birthing an artistic creation, as one whose body has been opened and closed.

What made Salvador Mallo's comeback possible, after years of withdrawal and his mother's death, was a string of events and meetings that led him to feel that he is seen, and restored his sense of personal wholeness. The possibility of being acknowledged and reflected by others becomes real with the invitation to a retrospective of his old film. There is an encounter with the hero of "Sabor", about whom he still harbored grievances all those years; a meeting with his old-time lover, whose appearance - height, hair, beard - mirrors the image of himself, and especially the picture of himself as a child, sent to him by Eduardo, his first great passion, who was introduced to Salvador Mallo by his mother, and now found his way to him, after so many years.

This painting of Salvador Mallo as a boy is another element that is only deciphered toward the end of the movie. Throughout the film, Salvador Mallo's love of art is apparent in a housefull of artworks, books about famous artists, and the way he describes paintings as welcoming friends during his years as a recluse. The significance of this painting only becomes clear at 
a later stage: Salvador Mallo's passion for Eduardo, the stonemason who loved to paint, and worked in the cave house in exchange for Salvador Mallo's teaching him to write. For the adult Salvador Mallo, the painting symbolizes a look returned: not only did he look at Eduardo with longing, but Eduardo looked at him and saw him. Symbolically, this reciprocity glance, reflected in the painting, enables him to overcome the danger of self-destruction, by restoring his trust in art as a source of real connection between people. The operation that reopens the cave-mouth symbolizes his return to the world, his ability to create and love again, his conquest of the fear of disappearing into the work, his renewed belief in a world that looks back at him and sees him.

In All That Jazz is the fear of disappearing as part of the creative process is articulated as a growing assimilation into the world of the movie itself, and consequently an ongoing disconnection from reality. The creative process is accompanied by exhilaration in the ability to create something new, but also by enormous anxiety over loss of self. To overcome his fear of loss of virility, Joseph “Joe" Gideon's sexuality finds an outlet with numerous women. $\mathrm{He}$ has difficulty establishing a lasting relationship, and almost every woman he meets is framed in a sexual context. There seem to be no reciprocal relationships with the women who pass through his life like commodities on a conveyor belt. In this respect, of the three movies, All That Jazz is closest to Fellini's $81 \frac{1}{2}$ in terms of its cinematic era, and its extreme endeavors to gain a sense of control by objectifying women.

The women in Fellini's film come from a variety of backgrounds, some that touch a memory, some that are part of a fantasy, and some that are part of Guido Anselmi's life at the present time. What is common to them all is that they are not regarded as individuals in their own right, but as women whose task it is to tend to Guido Anselmi's needs: to take care of him, to clean up after him, and to pleasure him sexually. Throughout the movie, until the last scene, ${ }^{4}$ this perception reigns, both in the narrative of the plot and in the world of the imagination. It is presented as stream of consciousness, on which the screenplay and the photography are based. In one scene, Guido Anselmi imagines his own harem, where he whips into line any woman who is displeased with the way he runs it. The role of his wife in the movie is to clean for him, whereas the sexuality of other women is the only criterion by which they are judged. Anyone no longer young enough is confined to the attic, out of sight, despite their protests and pleas. Only at the end of the film, when Guido Anselmi is able to place men and women equally on a circular stage, and in fact join them there, can he free himself of the sense of loss and being bogged down, and successfully make the movie.

Fosse's movie, in contrast to Fellini's, does not have as callous a fantasy of control and power of a man over a variety of women; yet, the hero is clearly presented as a womanizer, and the movie is populated by a profusion of women and just one man, who has an important place in their lives. The poster on Joseph "Joe" Gideon's bathroom wall that greets him every morning with the image of six bare-legged women, each a replica of the other, and a single man in a suit is one example. Another example is the repeated imaginary scenes in which the choreography calls for him to be in the center, surrounded by dozens of female dancers in identical costumes and makeup. Accordingly, the film does not pass today's Bechdel test,

\footnotetext{
${ }^{4}$ For most of the film and until the final scene, with apparent reconciliation to the idea of women as equals, as he holds hands with his wife.
} 
which asks whether at least two women in the film had a conversation about something other than a man (Agarwal et al., 2015).

The great involvement of the world of the stage in Joseph "Joe" Gideon's life, and his difficulty in committing to a relationship and distinguishing between his persona on stage and off it, makes it hard for him to believe in himself, and to assimilate the positive reviews. $\mathrm{He}$ is extremely sensitive to negative reviews, however, and the scathing criticism of his movie in a television review takes the wind out of his sails, beginning his downward spiral. ${ }^{5}$ The refuge he finds in the fantasy world, in which a huge audience gives him a standing ovation and congratulates him on his achievements, and in the conversation with the imaginary angel of death, who is ready to embrace him, demonstrates the possible devastation of sinking into the world of the imagination.

The final scene, in which the camera lingers over a transparent, zipped-up body bag, with the late Joseph "Joe" Gideon inside, violates the taboo on things that should remain unseen (Sobchack, 2004, pp. 226-257; Yosef, 2013). The point of view that Joseph "Joe" Gideon presents throughout the film transmits a feeling of lost boundaries, and his objectification by the producers and investors. When the camera tracks the process invasively, crossing boundaries from a multitude of angles, the body bag can be interpreted as protecting Joseph "Joe" Gideon, wrapping him up, away from constant exposure, from the persistent need to function and create, from the ever-present confusion between illusion and reality. The scene raises weighty questions about the meaning of power, and the gap between masculine appearance of power and the situation as it really is.

The character of Joseph "Joe" Gideon in the movie is of one who identifies with his creative world to the very end. This is a director whose work gives him meaning, identity, and public appreciation. All these yield only temporary support, however, whereas every process of a new work revives the sense of fragility, which the environment cannot always resolve and restore his feeling of wholeness. As long as the world of creative art gives content to his life and becomes his main anchor - and life, in all its aspects, swirls around the filmcraft - so the danger of being incarcerated and engulfed in the golden cage of his creations grows, until death is seen as the only salvation.

\section{Discussion and conclusions}

The ancient Greek analogy of the artistic creator as a life-giving father, and its transformations from early to modern times (Gilbert \& Gubar, 2020) conceals a double meaning of having the power to strengthen and to weaken at the same time. On the one hand, it enables an understanding of begetting a work in a process in which the director opens his mind and heart to the world; on the other hand, it allows an understanding of how the process of filmmaking can enfeeble the film-maker and induce a feeling of loss of self. This feeling of the disintegration of personal wholeness is manifested in all three films as the suffering of soul and body, whereas healing is described as the result of positive feedback the auteur receives

\footnotetext{
$\overline{5}$ In Fellini's movie, one of Guido Anselmi's imaginary ways to help him create is to kill his most lethal critic.
} 
from the audience and those around him. However, if that feedback is missing, the loss of self exacts a high price that can result in sickness or even death.

One of the flawed ways of restoring the feeling of male control, presented in the Fosse and Bentwich films, ${ }^{6}$ is the objectification of women. This attitude, whether in the reality of the film, or as part of a fantasy, is shown to bestow a temporary sense of control, while distancing the director from his inner truth, and from the ability to create a work that has real artistic reflection. It is a broken reed that endangers the artist in a balance-of-power system that, in the end, can devour him as well. From a broader perspective, all three films depict the sinking into a world of fiction as a trap of self-objectification, which can ensnare the absolute artist, paralyze him, and draw him even deeper into fantasy worlds of poisoned pleasure. In contrast, looking back from whence he came affords the artist a recognition and visibility that is presented in all three films as possessing the power of redemption from a situation of disintegration of the subject.

The absolute male director, as depicted in each of the films selected, is driven at one and the same time by an empowering dynamic, and a dynamic of potential failure. The point of departure of these dynamics is the absolute perspective of the director, for whom the world of cinema is perceived as all-inclusive, and the boundaries between fiction and reality are blurred. The director creating the film invests it with his inner world. While the work threatens the self with sinking into an illusory world, and the consequent disintegration of the self, it can also be a lifeline with the potential for forging connections with the world and with his surroundings. This is seen as a process that parallels childbirth and described accordingly, with the director presented as a penetrable and vulnerable body.

When the film is released, its success is also measured by the restoration of the director's sense of personal wholeness by the reciprocal look that reinforces his masculine and creative identity. Similarly, the release of the film and its positive reception are likely to reaffirm the relations between the director and the people in his life. The failure of the film to take off, scathing critical reviews, or the inability to attract feedback that will bolster the existence of the subject are described in terms of both emotional and physical illness. Being engulfed in a fictional world serves as an indicator of the disintegration of the self, conceptualized also as death, which in the fantasy world gives the feeling of recognition, admiration and visibility that was missing in the real world.

Age plays a significant role in this dynamic. The fact that the main character in all three films is middle-aged is important, insofar as it enhances the physical danger and the possibility of succumbing to a process of the disintegration of self and body. Behaviors of young adults (around age 20, for example) tend to be intense and single-minded, and neglect health issues that could afflict the body. At a later age, however, those kinds of behaviors could have serious health consequences (Umberson et al., 2010).

Absolute directors are so deeply involved in their work that they find it difficult to speak any language other than cinema, a fact that hinders communication. In Peaches and Cream that element is strongly felt in the use of street posters to advertise the movie, in an era in which the younger generation speaks "digital", a medium that is alien to Zuri Shostak and

\footnotetext{
${ }^{6}$ In both films, it is not only the directors that perceive women as objects to reinforce their masculinity, but the directors themselves are objects of interest for the women.
} 
leaves him behind. In Pain and Glory, ageing is framed as isolation at home, and withdrawal into the memories of the past that confine the director and prevent his communication with others. In All That Jazz, Joseph "Joe” Gideon's “totality” finds expression in his unwillingness to listen to the doctors and take them and his medical condition seriously. The only language he speaks is direction and choreography, and he transfers that conversation to the hospital, where he eventually pays for it with his life.

In conclusion, the approach regarding film-making as a mostly male preserve once again raises questions not only about male creativity, but also about the creative process among women. In her book, A Room of One's Own (first published in 1929), Woolf (2015, pp. 1-86) describes Shakespeare's fictional sister (Shakespeare, 2002), and the pitiful fate of a talented woman who received no recognition at all. The Shakespeares of our time may have talented sisters, who are still less famous and recognized than the men. In contrast to the ethos of the suffering male artistic genius, there is no common social structure regarding the suffering of the female artistic genius; the "absolute artist" is a term applied more to male creative artists than their female counterparts. Future research may examine female metafictional cinema that describes the creative experience through the eyes of women artistic creators.

\section{References}

Agarwal, A., Zheng, J., Vasanth Kamath, Sh., Balasubramanian, S., \& Dey, Sh. D. (2015, 31 May-5 June). Key female characters in film have more to talk about besides men: Automating the Bechdel Test. In Proceedings of the 2015 Annual Conference of the North American Chapter of the Association for Computational Linguistics: Human Language Technologies, N15-1084 (pp. 830-840). Denver, Colorado, United States. Association for Computational Linguistics. https://doi.org/10.3115/v1/N15-1084

Arendt, H. (1998). The human condition. The University of Chicago Press. https://doi.org/10.7208/chicago/9780226924571.001.0001

Bondanella, P. (2002). Cambridge film classics. The films of Federico Fellini. Cambridge University Press. https://doi.org/10.1017/CBO9780511613340

Borowsky Junge, M. (2016). History of art therapy. In D. E. Gussak \& M. L. Rosal (Eds.), The Wiley handbook of art therapy (pp. 7-16). John Wiley \& Sons, Ltd. https://doi.org/10.1002/9781118306543.ch1

Caughie, J. (Ed.). (2001). British film institute readers in film studies. Theories of authorship: A reader. Routledge.

Conti, I., \& McCormack, W. A. (1984). Federico Fellini: Artist in search of self. Biography, 7(4), 292308. https://doi.org/10.1353/bio.2010.0691

Gilbert, S. M., \& Gubar, S. (2020). The Madwoman in the Attic: The woman writer and the nineteenthcentury literary imagination. Yale University Press. https://doi.org/10.12987/9780300252972

Irigaray, L. (1993). Je, Tu, Nous: Toward a culture of difference. Routledge.

Kost, K. (2019). Fostering creativity for healing: A literature review on the use of art therapy and mindfulness with traumatized adults. Expressive Therapies Capstone Thesis, 149. https://digitalcommons. lesley.edu/cgi/viewcontent.cgi?article=1211\&context=expressive_theses

Land, van der S., \& Muntinga, D. G. (2014). To shave or not to shave? How beardedness in a Linke$d I n$ profile picture influences perceived expertise and job interview prospects. In F. Fui-Hoon Nah \& K. Siau (Eds.), HCI in Business, HCIB 2014. Lecture Notes in Computer Science, Vol. 12783 (pp. 257-265). Springer Nature Switzerland AG. https://doi.org/10.1007/978-3-319-07293-7_25 
Miller, D. L. (2016). Gender and the artist archetype: Understanding gender inequality in artistic careers. Sociology Compass, 10(2), 119-131. https://doi.org/10.1111/soc4.12350

Mulvey, L. (1989). Language, discourse, society. Visual and other pleasures. S. Heath, C. MacCabe, \& D. Riley (Eds.). Palgrave Macmillan.

Ne'eman, J. (2008). Vulnus: donum belli, Israel. Studia sionismi et civitatis Israelis - historia, societas, cultura. Israel: Studies in Zionism and the State of Israel - History, Society, Culture, 14, 105-125.

Papworth, M. A., Jordan, G., Backhouse, C., Evans, N., Kent-Lemon, N., Morris, J., \& Winchester, K. J. G. (2008). Artists' vulnerability to psychopathology: Towards an integrative cognitive perspective. Journal of Creative Behavior, 42(3), 149-163. https://doi.org/10.1002/j.2162-6057.2008.tb01292.x

Plato. (1968). The Republic. Basic Books, Inc.

Plato. (2003). Penguin classics. The symposium. Penguin.

Ramasubba Reddy, I., Ukrani, J., Indla, V., \& Ukrani, V. (2018). Creativity and psychopathology: Two sides of the same coin? Indian Journal of Psychiatry, 60(2), 168-174.

https://doi.org/10.4103/psychiatry.IndianJPsychiatry_129_18

Reed, J. A., \& Blunk, E. M. (1990). The influence of facial hair on impression formation. Social Behavior and Personality: An International Journal, 18(1), 169-175. https://doi.org/10.2224/sbp.1990.18.1.169

Shakespeare, W. (2002). As you like it. In R. Proudfoot, A. Thompson, \& D. Scott Kastan (Eds.), The Arden Shakespeare. Complete works (pp. 161-190). Cengage Learning.

Sobchack, V. (2004). Carnal thoughts: Embodiment and moving image culture. University of California Press. https://doi.org/10.1525/9780520937826

Staples, D. E. (1966-1967). The Auteur theory reexamined. Cinema Journal, 6, 1-7. https://doi.org/10.2307/1225411

Statista. (2021). Distribution of movie directors in the United States from 2011 to 2020, by gender. https:// www.statista.com/statistics/696871/movie-director-gender/

Sussman, A. (2007). Mental illness and creativity: A neurological view of the "Tortured Artist". Stanford Journal of Neuroscience, 1(1), 21-24.

Umberson, D., Crosnoe, R., \& Reczek, C. (2010). Social relationships and health behavior across life course. Annual Review of Sociology, 36, 139-157. https://doi.org/10.1146/annurev-soc-070308-120011

Ward Mahar, K. (2001). True womanhood in Hollywood: Gendered business strategies and the rise and fall of the woman film maker, 1896-1928. Enterprise and Society, 2(1), 72-110. https://doi.org/10.1093/es/2.1.72

Woolf, V. (2015). Oxford world's classics. A room of one's own and Three Guineas. A. Snaith (Ed.). Oxford University Press.

Yosef, R. (2013). Responsabilitas aspectum: reflexiones in ethica et documenta membra sequens Bill Nichols. Mikan, 13, 164-180. 